\title{
CONSTRUCTION LOGISTICS PLANNING BY SIMULATION
}

\author{
Julia Voigtmann \\ Hans-Joachim Bargstädt \\ Bauhaus-University Weimar \\ Marienstraße 7 \\ Weimar, 99423, GERMANY
}

\begin{abstract}
Construction logistics comprises planning, coordination and supervision of material flow to, within and from construction sites. Good construction logistics on construction sites saves time and construction costs. To plan construction logistics, numerous interferences between configuration of construction site and construction work have to be considered. In particular in outfitting processes, their countless possible work sequences and many involved companies govern production logistics. This complex system can be analyzed by simulation.

Nevertheless logistic systems on site are influenced by various factors, so that the determination of an optimal network configuration and organisational structure becomes not trivial. To find a useable solution requires countless simulation runs with many factor variations. Therefore an adequate simulation model, which enables network dimensioning and analysing organisational structure of logistic processes without programming, is essential. Furthermore the identification of qualified factor combinations depending on several process or building attributes and the elimination of irrelevant factors accelerate logistic planning.
\end{abstract}

\section{INTRODUCTION}

Construction logistics comprises planning, application, coordination and supervision of material flow to, within and from construction sites as a self-contained management function (Portatius 1997). Several parallel and independently existing supply chains cross on sites and interact. The higher-level planning and coordination is a difficult challenge, because companies are only interested in their own supply chains on sites.

Superordinated control and optimisation are not considered, which might take advantage of positive interdependencies between several supply chains. Traditionally in most companies, construction logistics tasks are performed by several different persons, of whom only a few are also occupied by the construction process itself. Insufficiently planned and noncoordinated logistic processes are the consequence and reasons for the high amount of non-productive actions and consequently disturbed work flow on construction sites. In consequence disorganized material storage causes extra time for the search of material or to rearrange storage areas.

Several studies on German construction sites pointed out, that approximately one third of the total execution time is consumed by logistic processes (Guntermann 1997). Boenert and Blömeke (2006) estimate the deducible optimization potential by well-planned and coordinated construction logistics up to 10 percent of construction time or 4 percent of building costs in outfitting processes.

To consider all logistic network elements (e.g. loading zones, builder's hoist, storage areas) and processes (e.g. store, transport, handle) on site and their influencing factors as a superior logistic network is a necessary challenge. 


\section{Voigtmann and Bargstädt}

\section{LOGISTIC NETWORK FOR CONSTRUCTION SITES}

Logistic management in construction industries was not considered very deeply in the past. One rason ist, that the planning and the construction processes are located at several contractual partners. Only in the planning of site facilities detailed logistics aspects are considered. This prevents the thinking in an overall logistic system.

To optimize the construction site logistic globally it is essential to consider all individual in-house supply chains and to combine them to a single global network. Elements of single supply chains become network elements (Figure 1). This enables to analyze all influencing factors and their effects on the logistic network configuration and the logistic organization structure (Voigtmann and Bargstädt 2008).

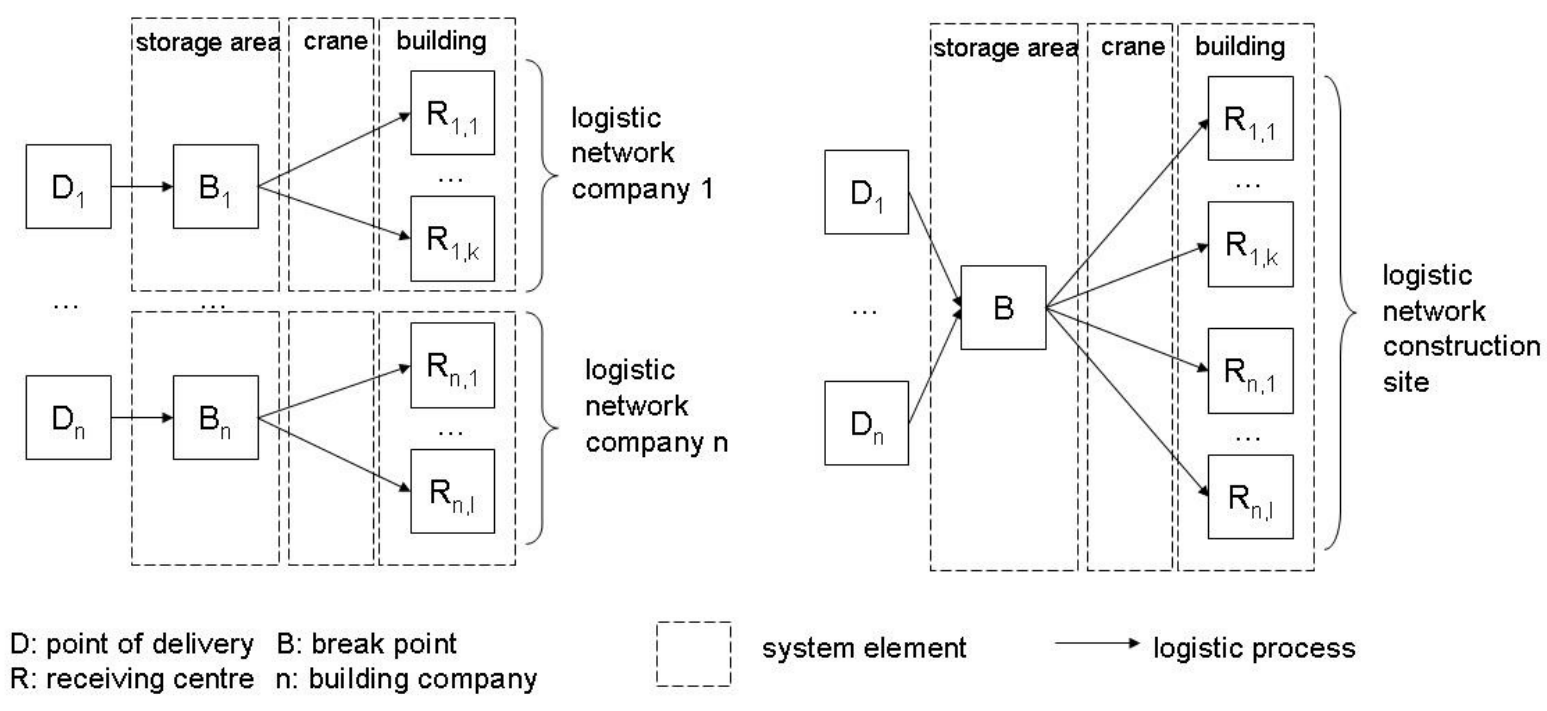

Figure 1: Individual supply chains vs. construction site logistic network

Higher-level approach generates far more optimization potential, but it increasing complexity of the system. To find a feasible network configuration and organizational structure, it is necessary to collect all relevant logistic factors. Not the peculiarities of in-house supply chains, but also interferences between individual logistic chains and between logistics and the construction processes have to be considered. All factors are highly variable in regard to type, time and spatial aspects (table 1).

Types of construction requirements for outfitting processes vary mainly in regard to vertical and horizontal material transport. For vertical transport cranes are predominant. Elevators, lifting platforms and high lift trucks are also alternatives to be considered. Horizontal transport can be facilitated by forklifts and transport containers on wheels. Pumping allows for both, horizontal and vertical transport. Manual transport, especially at small scale, is also common for outfitting processes and currently counts for a quite a big portion of overall working time.

Spatial variability is indicated by alternative positions of construction requirements. In comparison to structural work, the working areas during outfitting processes are literally scattered all over the building, because innumerable working positions are feasible. Furthermore, and especially in outfitting, the rescheduling of storage areas, the rearrangement of means of transportation and other major changes in layout are daily business. Often even the ways of access to the site is change. These changes are mainly caused by the work process itself. For example an unfinished room is first used for material storage, but has then to be made free for outfitting processes, which shell start in this room. A stairway is temporarily blocked, because of ongoing finishing works. 


\section{Voigtmann and Bargstädt}

Temporarily limited storage areas and positions of construction equipment indicate the necessary variability of the logistic system. It is mainly caused by the working process itself. Sometimes the use of lifts and other means of transportion is restricted. For example, after finishing the façade elements, outdoor elevators are dismantled, and all remaining transports have to be shifted to an inside elevator (Voigtmann et al, 2008).

Table 1: Variability of logistic influence factors (Bargstädt et al, 2010)

\begin{tabular}{|l|l|l|}
\hline variability & \multicolumn{1}{|c|}{$\begin{array}{c}\text { In-house factors by one individual } \\
\text { company }\end{array}$} & \multicolumn{1}{c|}{ factors between several companies } \\
\hline type & $\begin{array}{l}\text { company-owned site equipment, e.g. } \\
\text { specific transport equipment } \\
\text { type of construction work and resulting } \\
\text { logistic material and process characteris- } \\
\text { tics } \\
\text { Size and profile of working gang }\end{array}$ & $\begin{array}{l}\text { Shared use of site equipment, e.g. storage } \\
\text { areas, type of transportation equipment } \\
\text { site location and resulting logistic influ- } \\
\text { ences } \\
\text { organization form and responsibilities for } \\
\text { logistic activities and their coordination }\end{array}$ \\
\hline time aspects & $\begin{array}{l}\text { utilization periods of company-owned } \\
\text { site equipment } \\
\text { construction time and scope of work } \\
\text { material delivery dates }\end{array}$ & $\begin{array}{l}\text { utilization periods of sharedly used site } \\
\text { equipment } \\
\text { gang sequences, construction sequence, } \\
\text { time coordination and planning }\end{array}$ \\
\hline $\begin{array}{l}\text { Spatial as- } \\
\text { pects }\end{array}$ & $\begin{array}{l}\text { placement of company-owned site } \\
\text { equipment } \\
\text { work sequences and working direction }\end{array}$ & $\begin{array}{l}\text { placement of commonly used site equip- } \\
\text { ment } \\
\text { gang sequences, construction sequence, } \\
\text { coordination of space allocation }\end{array}$ \\
\hline
\end{tabular}

The interrelations between construction processes and logistics as well as the large variability of logistics in outfitting processes and of outfitting processes itself make logistic planning a highly complex optimization problem. It is not surprising that a large number of possible solutions exists for several logistic functions, e.g. delivery, storage, transport of material. Optimizing only partial aspects might be counterproductive, if the improvement for one special problem or situation has unfavourable influences on other tasks. For example, the arrangement of an additional unloading area might reduce waiting time for delivery vehicles on a construction site, but may require an additional crane, and thus cause additional costs. Or if material storage shall be very close to the workspace, multible rearrangement activities might be required. Such conflicts of interest are not unusual in logistics. They result in problems of multidimensional optimization. (Voigtmann et al, 2008).

To analyze such complex systems, that are driven by the working processes, by logistics activities on construction sites and by their interferences and influences, simulation is a suitable tool (Verein Deutscher Ingenieure, 1993).

\section{SIMULATION OF CONSTRUCTION LOGISTICS}

\subsection{Demands on the simulation model}

To analyze practicable logistic network configurations, the simulation model must respects the specialties of construction processes and their logistic activities. In comparison to stationary industry, work on site is typical for its non permanent working areas. Therefore the exact location of working areas has to be taken 


\section{Voigtmann and Bargstädt}

into account, when modeling logistic activities with sufficient accuracy. The chosen model enables in an easy way to simulate construction, especially outfitting processes with several different characteristics. The adaptation of the model to a special construction site should be possible without programming (Voigtmann et al, 2008). The dimensioning of the site equipment elements and the structuring of the logistic organization is done in a simple way. Table 2 shows the most important input data (characteristics of construction processes, site, material and logistic strategies and organizational structure) to simulate logistic activities on site.

Table 2: Important input data

\begin{tabular}{|c|c|}
\hline Input data for & Examples \\
\hline assembly & $\begin{array}{l}\text { point of assembly, dimensions, workers (number and qualification), } \\
\text { assembly duration }\end{array}$ \\
\hline work order (constraints) & $\begin{array}{l}\text { order of work steps (on material basis or on basis of structural com- } \\
\text { ponents), order of assembly of structural components (needed prede- } \\
\text { cessors) }\end{array}$ \\
\hline process & $\begin{array}{l}\text { work area, safety zone, accessibility after work (area blocked com- } \\
\text { pletely, closed for storage, etc.), etc. }\end{array}$ \\
\hline personnel & performance characteristics (number, working hours, qualification) \\
\hline equipment & $\begin{array}{l}\text { type (number, location, working hours, relevant technical data for } \\
\text { construction, requirement elements) }\end{array}$ \\
\hline material & $\begin{array}{l}\text { transport characteristics (dimensions, weights, stackability, delivery } \\
\text { characteristics) }\end{array}$ \\
\hline organizational structure & responsibilities (for several logistic activities, priorities) \\
\hline logistic Strategies & $\begin{array}{l}\text { delivery (number, date of delivery, transportation device, dimen- } \\
\text { sions, kind of material) } \\
\text { storage (number, use period, location, accepted user) } \\
\text { disposal (disposal rhythm, capacity) } \\
\text { transports (responsibilities, capacities, priorities, channelization) }\end{array}$ \\
\hline
\end{tabular}

To evaluate a chosen network configuration, the recording of several data of the construction process is required. This includes the total construction time, working time and further time slices of workers. In particular the recording of time slices caused by logistic activities (for material transport, clean up, relocation, ways) will allow the identification of bottlenecks and other surplus items.

\subsection{Simulation model}

The presented approach starts out from a simulation model, which is used to display construction processes, especially outfitting processes. The constraint-based model has been developed by König et al. to analyze construction processes and work orders (König, Beißert, and Bargstädt 2007a; König, Beißert, and Bargstädt 2007b). The fundamental idea is, that work steps can only start, when certain necessary constraints are fulfilled. The model is implemented by the Simulation Toolkit Shipbuilding (STS) of the SimCoMar community (SimCoMar, 2010; Steinhauer, 2007) and uses Tecnomatix Plant Simulation (Siemens UGS, 2010). 


\section{Voigtmann and Bargstädt}

Users are enabled to model and simulate several outfitting processes and basic logistic activities using the included STS simulation framework. All STS components are interlocked. They simulate work steps and additional activities to perform the construction work (König, Beißert, and Bargstädt 2007a).

To integrate detailed logistic activities for construction sites a logistic control component is developed. The new component for logistic characteristics manages all logistic activities in interaction with the other components for the construction process. It considers site, material and logistic strategies and organizational structure. During the simulation the relevant data are recorded in order to analyze the effects of several logistic network alternatives. All logistic activities are automatically started by the logistic control component. The generation of rearrangement activities is exemplarily shown in Figure 2 (Bargstädt, 2010).

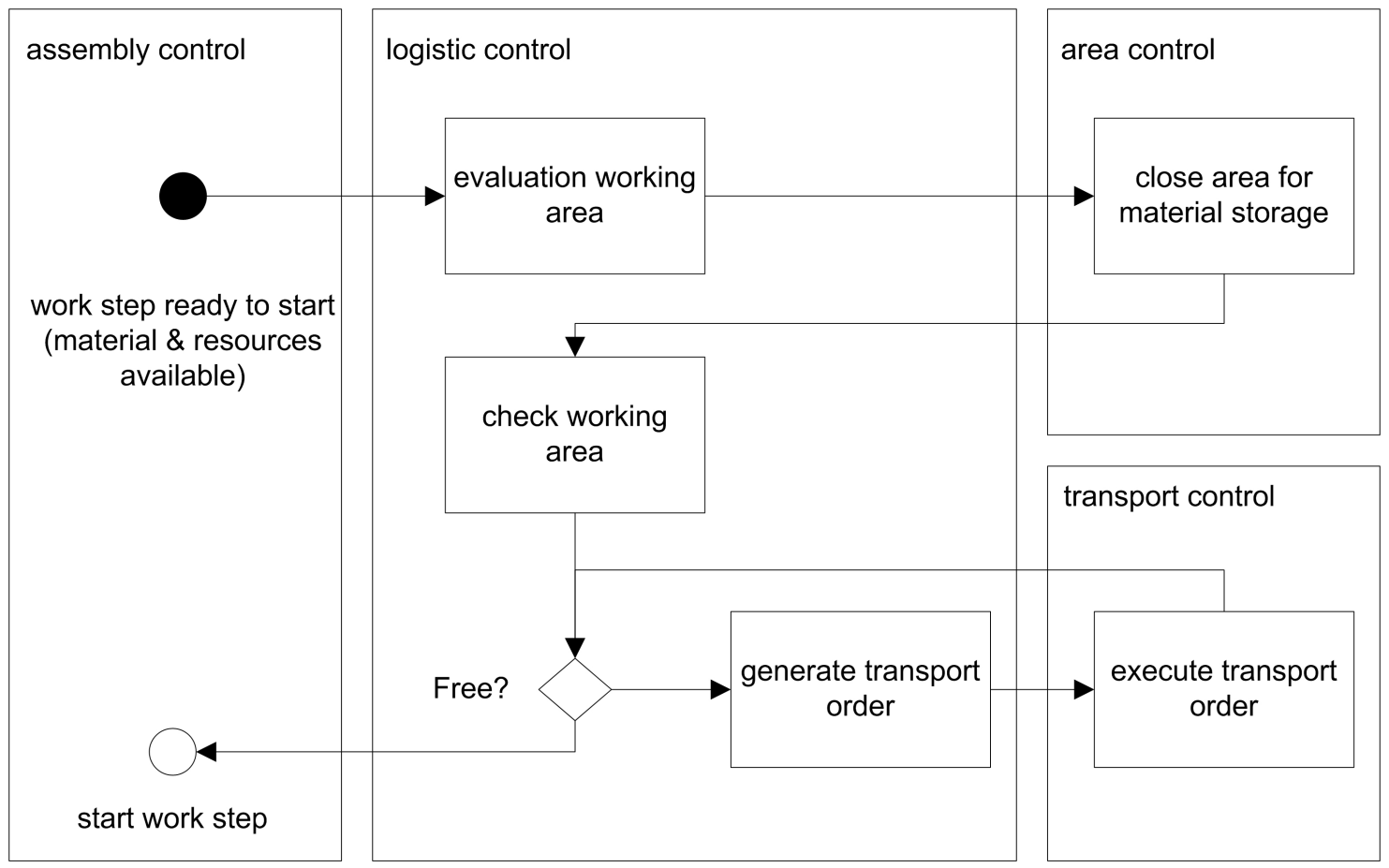

Figure 2: Interaction between components (Bargstädt, 2010)

The choice of an organizational structure for logistic subsystems is provided on the logistic control panel component by user interface. For each subsystem some present logistic strategies are available, e.g. material delivery strategies (delivery of all material at the beginning, by schedule, on call etc.) and storage strategies (central storage area, storage close to work areas etc.). The dimensioning of the site equipment (e.g. localization, capacity of builder's hoists) is similarly done by user interfaces for site elements, which are represented in the standard program or as special STS elements. 


\section{Voigtmann and Bargstädt}

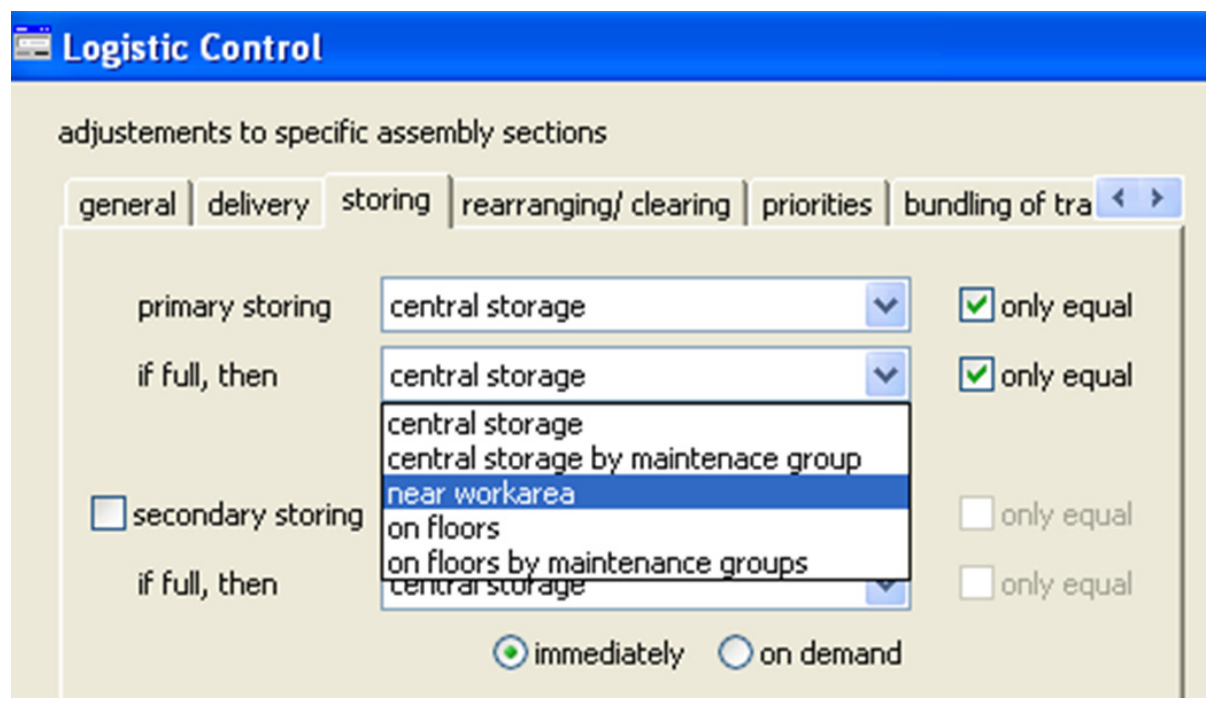

Figure 3: Logistic Control user interface (Screenshot)

So the model easily enables the user to dimension the network and to analyze the organisational structure of logistic processes, considering various influence factors and their variability.

\subsection{Application possibilities and limitations}

The simulation model has two main fields of application: the dimensioning of construction site elements and the selection of useable logistic strategies and organizational structures.

Construction site elements are variable by number, location and capacities. Specially for storage areas the period of use and the user group are selectable. Several logistic strategies are predefined. The different strategies can be attached to different work gangs. This leads to a large variety of parameters and options to configure the logistic network with its elements and organizational structure.

By defining different systematic work orders their effects on logistic activities can be analyzed. Evaluation criteria can be total construction time, minimal placement and constant resource efficiency. Costs can also be allocated to time, storage and efficiency parameters. The strength of a certain network configuration or logistic strategy is only evaluable by comparing several settings. Information about the suitability of work sequences can not be given directly, because work sequence in this case is part of the input data (defined by the technical constraints).

The model can be used to generate delivery schedules, overview tables of storage areas and operation schedules for personnel and site equipment. Applications in training sessions and for analyzing what-ifscenarios are possible, too.

\section{EXAMPLE}

\subsection{Model application}

The example shows a standard office building (Figure 4) with eight floors and 16 sections (two on each floor). All tasks have to be performed in all 16 sections. The overall work sequence is: first floor left, first floor right, second floor left, second floor right and so on. Work sequences within these sections are free, but they are due to the availability of material at the work areas, and also constraints for transport sequence and accessibility of work areas must be respected. 


\section{Voigtmann and Bargstädt}
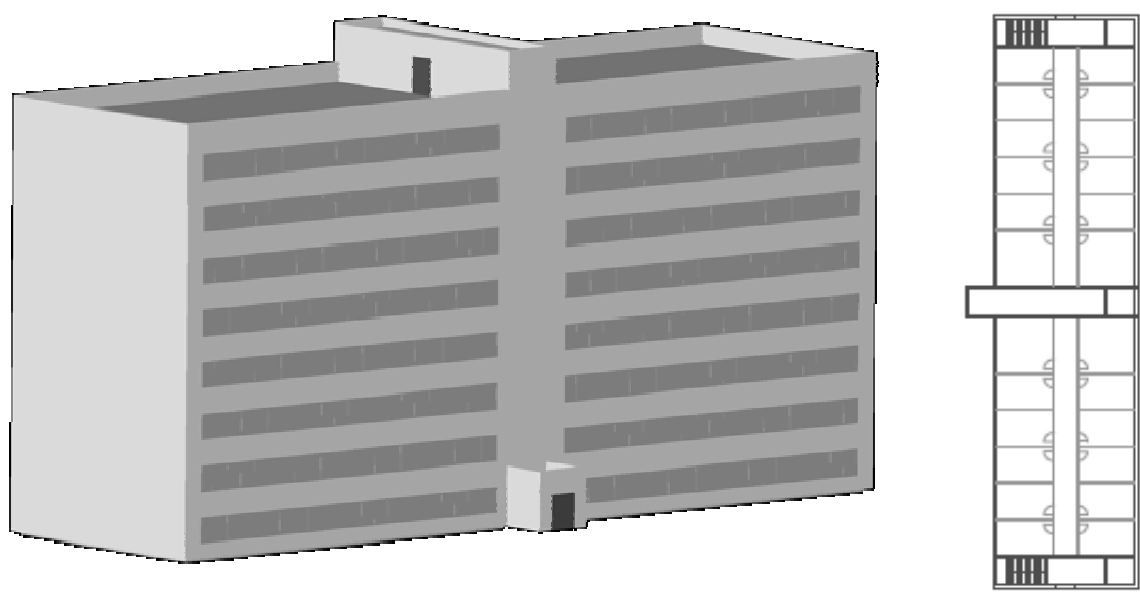

Figure 4: Simulated administration building (left: view, right: ground floor plan)

All floors can be reached by stairs at the ends of the building and by an elevator in the middle of the building. Access to the building on first floor is next to the stairs as well as an additional entry in the middle of the building. Vertical material transport is only by the elevator, personnel can use stairs or elevator to reach the floors. The decision is take on the basis of the distance to stairs or elevator and by accessibility.

To pinpoint the effects of changing configurations, the analysis is limited to one outfitting task (flooring) for each simulation run.

\subsection{Network configuration and scope of research}

In the examined example all material is delivered at the start of construction (delivery strategy). There a two unloading areas in front of the building near to the main entrance. After unloading the material is transported to the floors (decentralized storage strategy). Storage areas are located next to the lift on each floor. The transport to the installation areas starts as soon as the corresponding work step is ready to start (all other constraints are fulfilled, the work area is free of other materials). If necessary, the material is transported close to installation point.

All logistic activities are done by workers themselves. The activities are priorised as following (higher priority $=$ favored execution): construction task (1), material transport to storage/installation area (2), clean up and rearrangement (3) and unload (4). Low priority of construction results from urgency of logistic activities. If work areas or material are not available, they constrain the construction processes.

Using the example of flooring, the effects of diversified equipment can be demonstrated. Table 3 shows modified parameters. 


\section{Voigtmann and Bargstädt}

Table 3: Experiment overview

\begin{tabular}{|l|l|}
\hline \multicolumn{1}{|c|}{ Experiment $\mathbf{N r}$} & \multicolumn{1}{c|}{ modified parameter } \\
\hline 1 & None (basic network configuration) \\
\hline 2 & Lift speed increased to $0.5 \mathrm{~m} / \mathrm{s}$ \\
\hline 3 & Lift speed increased to $1 \mathrm{~m} / \mathrm{s}$ \\
\hline 4 & Lifting capacity increased to $350 \mathrm{~kg}$ \\
\hline 5 & Lifting capacity increased to $500 \mathrm{~kg}$ \\
\hline 6 & Lift position modified (shifted to left end of building) \\
\hline
\end{tabular}

To evaluate the applicability of the result to other maintenance groups, all six experiments respected with another construction task: drywall construction (experiment Nr. 7 - 12). The network configuration, organisational structure and the simulated building and its ground floor plan remain unmodified.

\subsection{Data interpretation}

The effects of modification in the network configuration, respectively modified site element parameters, are analyzed with regard to the required logistic time and construction time. All results are noted as percental improvement to the basic network configuration. Table 4 subsumes all results.

Table 4: Experiment results

\begin{tabular}{|c|r|r|r|r|r|}
\hline $\begin{array}{c}\text { experiment } \\
\mathbf{N r}\end{array}$ & \multicolumn{2}{|c|}{ flooring } & $\begin{array}{c}\text { experiment } \\
\mathbf{N r}\end{array}$ & \multicolumn{2}{c|}{ drywall construction } \\
\hline & $\begin{array}{c}\text { deviation in } \\
\text { logistic time } \\
{[\%]}\end{array}$ & $\begin{array}{c}\text { deviation in } \\
\text { construction } \\
\text { time [\%] }\end{array}$ & & $\begin{array}{c}\text { deviation in logis- } \\
\text { tic time [\%] }\end{array}$ & $\begin{array}{c}\text { deviation in } \\
\text { construction } \\
\text { time [\%] }\end{array}$ \\
\hline 1 & - & - & 7 & - & - \\
\hline 2 & $-44,2 \%$ & $-12,4 \%$ & 8 & $-9,8 \%$ & $-0,4 \%$ \\
\hline 3 & $-50,1 \%$ & $-11,4 \%$ & 9 & $-45,3 \%$ & $-2,3 \%$ \\
\hline 4 & $-6,1 \%$ & $+0,2 \%$ & 10 & $+0,6 \%$ & $+/-0 \%$ \\
\hline 5 & $+1,8 \%$ & $+0,6 \%$ & 11 & $+0,1 \%$ & $+/-0 \%$ \\
\hline 6 & $+5,1 \%$ & $-3,3 \%$ & 12 & $+3,2 \%$ & $+0,2 \%$ \\
\hline
\end{tabular}

The example show that there is no obvious correlation between used logistic time and necessary construction time. The differences because of the unregulated work order within the construction sections is predominant. The work sequence, however, is according to the availability of material at the work areas. With better elevator characteristics, the material is more available at the work areas. Especially in the flooring processes it is then possible, that first rugs are installed (e.g. on corridors), which do hinder work in downstream areas (rooms). In other case additional waiting time and finally longer construction time would be the consequence.

Another reason for higher logistic activities in case of increased lift parameters is, that the materials for both construction sections is stored in the same storage area. In this case faster material delivery on the floors causes additional need for rearrangement. 


\section{Voigtmann and Bargstädt}

Hence two important facts are distinguishable: Good logistics respectively well planned network configurations can not improve unfavorably chosen work sequences. To install rugs in corridors before installing in the rooms leeds to congestion. If only one network element is improved, e.g. site equipment, without consideration of other logistic elements, it might even act counterproductively.

A number of more then 150 experiments based on the basis configuration 1 to 12 with modified floor numbers and process times per piece show similar effects, but in different intensity. These effects neglected, another result is evidently: the higher the share of logistic activities is in construction time (less floors or process times) the better its optimization potential is realizable. But not all activities profit from the optimization at the same rate. Especially in the simulation of drywall the effects are obvious (figure 5). The cycle time of an elevator has very obvious influence, whereas the position of the elevator hat neglectable consequences.
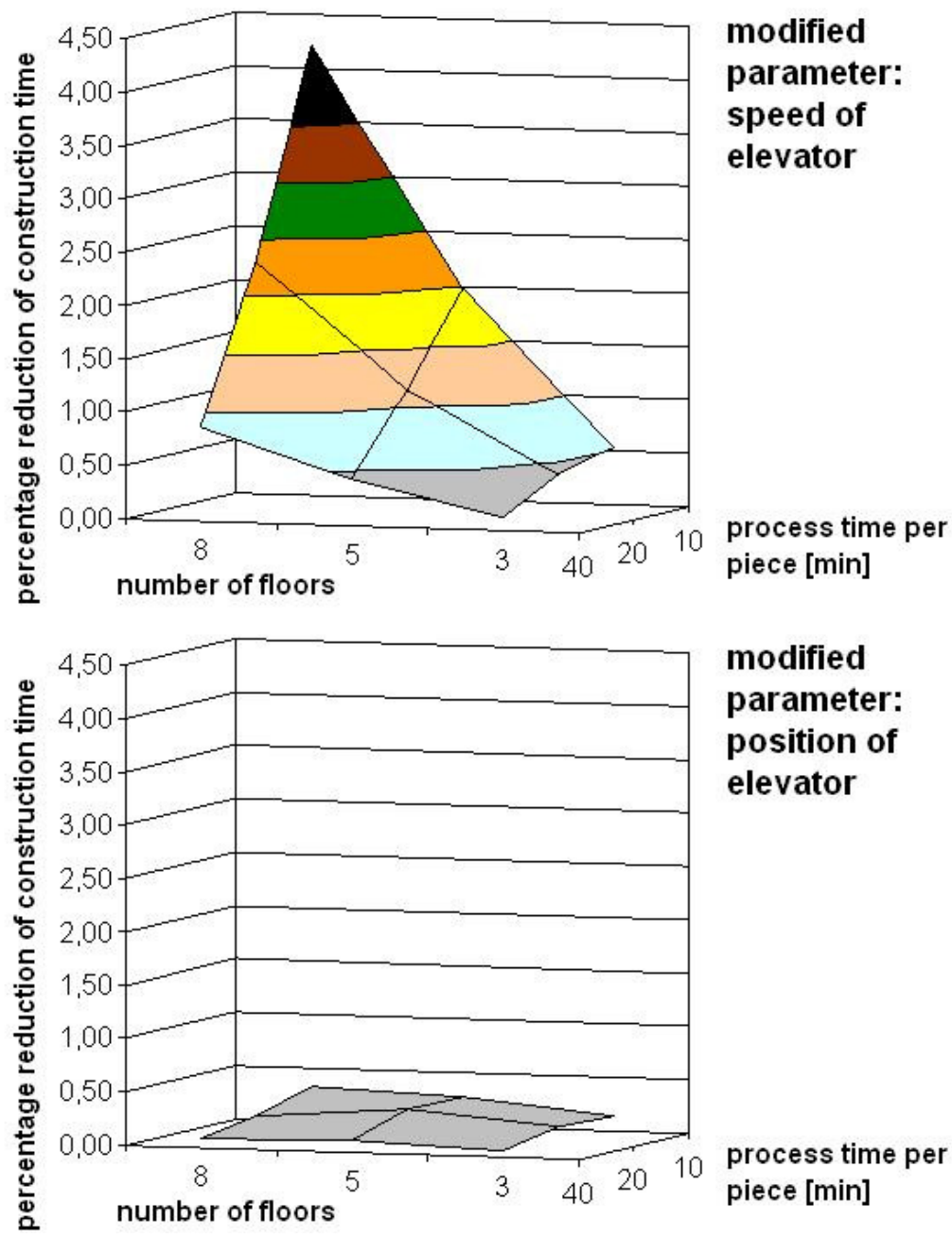

Figure 5: Dependency of construction time reduction on floor numbers and process time per piece

\section{DISCUSSION AND CONCLUSION}

Optimization of construction site logistics cannot be achieved by a straight forward simulation run. To improve an initial logistics configuration of a construction site, several simulation runs with various factor 


\section{Voigtmann and Bargstädt}

adjustments have to be executed. Therefore an initial feasible solution and the knowledge about the major factors of influence are inevitable.

First simulation experiments based on a given site configuration pointed out, that several factors influence the percentage of logistic activities and finally the productivity on site in different order of magnitude. To accelerate logistics planning, the elimination of irrelevant factors will be advantageous. It minimizes experimental scheduling and the number of simulation runs. The identification of typical qualified factor combinations, which depend on several processes and building attributes, secures optimisation potential and makes it quickly accessible.

It is obvious, that reducing logistic activities, does not always result in reduced construction time. An insufficiently planned work order can not be improved by a purely logistic planning.

\section{REFERENCES}

Bargstädt, H.-J. and J. K. Voigtmann. 2010. Simulationsgestützte Logistikplanung für Baustellen. In: 5. Wissenschaftssymposium Logistik, ed. Bundesvereinigung Logistik e.V., Darmstadt: in press.

Boenert, L. and M. Blömeke. 2006. Kostensenkung durch ein zentrales Logistikmanagement. In: Baulogistik - Konzepte für eine bessere Ver- und Entsorgung im Bauwesen, ed. U. Clausen, 29-41. Dortmund: Verlag Praxiswissen.

Guntermann, B. 1997. Schlüsselfertiges Bauen: Logistik im Ausbau bei schlüsselfertiger Bauausführung. Diplomarbeit. Universität Dortmund. Dortmund.

König, M., U. Beißert and H.-J. Bargstädt. 2007a. Constraint-Based Simulation of Outfitting Processes in Ship Building and Civil Engineering. In: Proceedings of the 6th EUROSIM Congress on Modelling and Simulation - Vol. 2: Full papers (CD), ed. B. Zupančič, R. Karba and S. Blažič, S. 11. Ljubljana, Slovenia: SLOSIM - Slovene Society for Simulation and Modelling.

König, M., U. Beißert and H.-J. Bargstädt. 2007b. Visual Simulation - An Appropriate Approach to Support Execution Planning in Building Engineering. In: Proceedings of 7th International Conference on Construction Applications of Virtual Reality, ed. Pennsylvania, USA: Pennsylvania State University, USA.

Portatius. 1997. Baulogistik. In: Vahlenss großes Logistiklexikon, ed. J. Bloech, 187-189. München u.a.: Beck.

Siemens UGS. 2010. <http://www.emplant.de/> [accessed 27.03.2010].

SimCoMar. 2010. <www.simcomar.com> [accessed 30.03.2010].

Steinhauer, D. 2007. Simulation im Schiffbau und Kooperation mit der Bauhaus-Universität Weimar. In: 1. IBW Workshop Simulation in der Bauwirtschaft, ed. V. Franz, 1-14. Kassel: kassel university press.

Verein Deutscher Ingenieure. 1993. VDI 3633 Blatt 1: Simulation von Logistik- Materialfluß- und Produktionssystemen, Grundlagen. Düsseldorf: Beuth.

Voigtmann, J. K. and H.-J. Bargstädt. 2008. Simulation of Construction Logistics in Outfitting Processes. In: EWork and EBusiness in Architecture, Engineering and Construction: ECPPM 2008, ed. A. Zarli and R. Scherer, 195-203. London: Taylor \& Francis Group.

\section{AUTHOR BIOGRAPHIES}

JULIA KATHARINA VOIGTMANN is a civil engineer. After her diploma in Weimar she work at STREIF Baulogistik GmbH, Essen, Germany. Her daily work focussed on construction logistic planning. Four years ago she went back to the university to do her dissertation on the chair of construction engineering and management at the Bauhaus-University in Weimar.

She is taking her doctoral degree in Civil and Structural Engineering in the field of process modelling and simulation. The objective of the dissertation is to analyse qualified logistic strategies depending on sev- 


\section{Voigtmann and Bargstädt}

eral process or building attributes by simulation. Therefore she developed a simulation model to simulate logistic activities on site. Her email address is <julia.voigtmann@uni-weimar.de>.

HANS-JOACHIM BARGSTAEDT is Professor for Construction Engineering and Management at the Bauhaus-University Weimar. He studied in Braunschweig, Atlanta and Marseille. He got his Ph. D. from the Technical University Braunschweig in 1988.

He worked 3 years in structural engineering offices. After his $\mathrm{Ph}$. $\mathrm{D}$. he worked more than 10 years for an international construction company. There he was responsible site engineer, site manager and project manager for several projects. As branch manager and director of a branch office he managed many different projects as dry docks, harbor construction and bridges as well as hotel and office buildings, and construction in the built environment.

Since 2000 he is Professor at the Bauhaus-University Weimar. His research fields are construction processes, construction management, simulation in construction, construction in the built environment and lifecycle considerations. E-mail is <hans-joachim.bargstaedt@uni-weimar.de> . 